\title{
Hesperitin enhances the ability of daunorubicin by co-loading with MPEG-PCL nanoparticles to induce apoptosis in gastric cancer
}

\author{
Lin-Lin Zhen ${ }^{1}$, Tian-Heng Ma ${ }^{2}$, Jin-Hai Tang ${ }^{3}$, Tian-Fang Xia ${ }^{4}$, Jie Ge ${ }^{5}$, Wei-Ji Yuan ${ }^{5}$, \\ Luo Chen ${ }^{5}$, Rang Wan ${ }^{5}$, Jing-Xiang Cheng ${ }^{5}$, Zhi-Kang Chen ${ }^{5}$, Zhi-Hua Cheng ${ }^{5}$ and \\ Wei Song ${ }^{6}$ \\ ${ }^{1}$ Department of Gerontology, Huai'an First People's Hospital, Nanjing Medical University, Huai'an 223300, China \\ ${ }^{2}$ Department of Gastroenterology, Huai'an First People's Hospital, Nanjing Medical University, Huai'an 223300, China \\ ${ }^{3}$ Department of Gastroenterology, Jiangsu Provincial People's Hospital, Nanjing 223300, China \\ ${ }^{4}$ Department of Gastrointestinal Surgery, Huai'an First People's Hospital, Nanjing Medical University, Huai'an 223300, China \\ ${ }^{5}$ Laboratory Medicines, Naning Biohelper Biotech Co., Ltd., Nanjing 223300, China \\ ${ }^{6}$ Department of Thyroid Breast Surgery, Huai'an First People's Hospital, Nanjing Medical University, Huai'an 223300, China \\ Correspondence to: Wei Song, email: 1244311976@qq.com, doctorsw@163.com \\ Keywords: hesperitin; daunorubicin; assembly method; gastric cancer; drug target \\ Received: June 24, $2017 \quad$ Accepted: August 27, $2017 \quad$ Published: October 31, 2017 \\ Copyright: Zhen et al. This is an open-access article distributed under the terms of the Creative Commons Attribution License 3.0 \\ (CC BY 3.0), which permits unrestricted use, distribution, and reproduction in any medium, provided the original author and source \\ are credited.
}

\section{ABSTRACT}

Tumor targeting delivery system has been suggested as an attractive strategy against tumor progression. And combination chemotherapy is essential and effective in preventing gastric cancer. Hesperitin (HE) has been suggested to exhibit anticancer ability through inducing apoptosis in many tumors without obvious toxicity, and it exerts synergistic anti-cancer ability with other drugs. Clinical application of daunorubicin (DA) in treatment of various cancers has been restricted. Targeted delivery of anti-cancer drugs could reduce their off-target effects and promote their efficacy. In our paper, HE and DA co-loaded methoxy poly (ethylene glycol)-poly( $\varepsilon-$ caprolactone) (MPEG-PCL) nanoparticles were prepared through an assembly method. The morphology, particle size (about $38 \mathrm{~nm}$ ), zeta potential, release profile in vitro, cell proliferation and cytotoxicity effects were investigated. The results suggested that HE and DA could be efficiently loaded into MPEG-PCL nanoparticles synchronously, and in vitro study indicated that they could be released from the nanoparticles in an extended period. in vitro, HE/DA/MPEG-PCL exerted an enhanced cytotoxicity and high apoptosis-inducing activities of gastric cancer cells. Importantly, HE/DA/MPEGPCL exhibited better cancer targeting and accumulation, enhancing the anti-tumor efficacy with little toxicity. Together, HE/DA/MPEG-PCL promoted the drug target on tumor site with preferable anti-tumor effects, which could be a promising therapeutic strategy against human gastric cancer.

\section{INTRODUCTION}

Gastric cancer is a frequently occurring cancer, and responsible for $\sim 989,600$ novel diagnoses and $\sim 738,000$ cases of mortality worldwide annually [1,2]. The majority of patients admitted to hospital are in the advanced stage of gastric cancer and less than $1 / 2$ of these patients survive for $>5$ years $[3,4]$. Chemotherapy is, presently, the most 
common therapeutic method to treat gastric cancer. However, a variety of chemotherapeutic drugs fail to prevent cancer progression, which is mainly due to severe systemic toxicity, the nonselective tumor accumulation, as well as multidrug resistance [5-7]. Thus, effective therapeutic strategies are urgently necessary to suppress gastric cancer. Accordingly, combination treatment with nanotechnology accompanied with traditional chemotherapy is reported as a promising strategy against cancer [8].

Nanotechnology plays an essential role in drug delivery systems, which could improve anticancer efficacy and attenuate the side effects of various chemotherapeutic drugs [9, 10]. Nano-materials, including polymeric micelles, and liposomes, have been widely used as important carriers to deliver hydrophobic drugs $[11,12]$. Particularly, the self-assembled polymeric micelles have attracted researchers' attention due to their promising vehicles for delivery of drug in cancer therapy [13]. Polymeric micelles have a typical core-shell structure, and in which hydrophobic drugs could be solubilized and stabilized in hydrophobic inner core of micelles [14, 15]. Further, the hydrophilic outer shell could improve the steric stabilization and extend the circulation time [16]. Generally, polymeric micelles could effectively and selectively accumulate in tumor site through enhanced permeability and retention effect, thus promoting the therapeutic strategies of chemotherapeutic drugs $[17,18]$.

Hesperidin (HE, Figure 1A) is one of the bioflavonoids, which is abundantly found in Citrus species and is the major active constituent of tangerine (Citrus reticulata) as well as sweet orange (Citrus sinensis) peel $[19,20]$. Hesperetin has been suggested to exhibit biological activities of anti-cancer, anti-oxidant, antiinflammatory and chemo-preventive properties for codelivery [21-23]. The clinical use of HE has been limited owing to their low water solubility and bioavailability in vivo. The solubility of $\mathrm{HE}$ in water was only $8.03 \mu \mathrm{g} / \mathrm{mL}$ [24]. And the poor bioavailability of hydrophobic drugs requires high concentrations to overcome sub-therapeutic levels in blood [20, 25]. Daunorubicin (Figure 1B) is widely used in the treatment of cancers through inducing arrest cell growth and apoptosis [26]. Disappointedly, the clinical application of DA is limited due to its severe side effects, such as cardiotoxicity, bleeding, and gastrointestinal disorders $[27,28]$. Thus, it is important to explore a novel formulation to the co-deliver HE and DA to prevent gastric cancer effectively considering their high hydrophobicity and side effects, respectively.

In the present study, HE and DA were encapsulated using PEG-PCL micelles, contributing to the generation of $\mathrm{HE} / \mathrm{BA} / \mathrm{M}$ nano-micelles. Next, the effect of $\mathrm{HE} /$ $\mathrm{BA} / \mathrm{M}$ nano-micelles on human gastric cancer cells was investigated. PEG-PCL micelles based on HE/DA conjugates were developed for targeting delivery and enhancing the anti-cancer efficacy of DA. HE/BA/M nanoparticles effectively suppress gastric cancer cells proliferation through inducing apoptosis, and in vivo C57BL6 mice and SGC7901-tumor bearing nude mice were applied to further explore the pharmacokinetic behaviors, antitumor effects, bio-distribution, as well as the toxicity of $\mathrm{HE} / \mathrm{BA} / \mathrm{M}$ nanoparticles. Our findings indicated that $\mathrm{HE} / \mathrm{BA} / \mathrm{M}$ nanoparticles supplied an effective formulation of $\mathrm{HE}$ and DA, which might be a promising therapeutic strategy for gastric cancer treatment in future.

\section{RESULTS}

\section{The preparation of daunorubicin-hesperitin- MPEG-PCL (HE/DA/M) nano-micelles}

In our study, the HE/DA/M nanoparticles were first made via a two-step self-assembly protocol. From Figure 1C, HE and MPEG-PCL copolymer were dissolved together in acetone. Then, the organic phase was evaporated using a rotary evaporator, which was performed under the reduced pressure. Following, the core-shell structured hesperitin-MPEG-PCL nanoparticles were formed through water addition using the core-encapsulated hesperitin. Subsequently, PBS and DA solution were added into the mixture of hesperitin-MPEG-PCL nanoparticles under mechanical stirring persistently, which contribute to the formation of daunorubicin-hesperitin-MPEG-PCL (HE/DA/M) nanoparticles. The core-shell structured daunorubicin-hesperitin-MPEG-PCL nanoparticles were created using core-encapsulated $\mathrm{HE}$ and DA via the selfassembly procedure of DA, HE and MPEG-PCL. Next, the nanoparticles of $\mathrm{HE} / \mathrm{DA} / \mathrm{M}$ were further characterized. The transmission electron microscopy (TEM) was used to observe the morphology of HE/DA/M nanoparticles (Figure 1D). The particle size distribution of freshly-prepared HE/ DA/M nanoparticles was exhibited in Figure 1E. The mean particle size was $38 \mathrm{~nm}$, which revealed the narrow particle size distribution of HE/DA/M nanoparticles. As shown in Figure $1 \mathrm{~F}$, the zeta potential of nanoparticles was $-8.9 \mathrm{mv}$.

\section{The assessment of drug release in vitro}

In this regard, we attempted to explore the release profiles of HE/M nanoparticles, DA/M nanoparticles, as well as HE/DA/M nanoparticles in PBS with PH 7.4 at $37^{\circ} \mathrm{C}$ containing $10 \% \mathrm{FBS}$. As shown in Figure $2 \mathrm{~A}$ and $2 \mathrm{~B}$, we found that both $\mathrm{HE}$ and DA could be released from HE/DA/M nanoparticles. However, the cumulative release rates of $\mathrm{HE}$ and $\mathrm{DA}$ from $\mathrm{HE} / \mathrm{DA} / \mathrm{M}$ nanoparticles were much slower in comparison to the HE/M nanoparticles and DA/M nanoparticles singly.

\section{HE/DA/M suppressed the cell viability of gastric cancer cells}

In this experiment, gastric cancer cell lines of SGC7901 and MGC803 were implicated to evaluate 
the anti-cancer effects of HE/DA/M nanoparticles. Therefore, a 24-h dose-dependent study was conducted. $\mathrm{HE} / \mathrm{M}$ nanoparticles, DA/M nanoparticles and $\mathrm{HE} /$ $\mathrm{DA} / \mathrm{M}$ nanoparticles were exposed to gastric cancer cells at the indicated concentrations. As shown in Figure $3 \mathrm{~A}$ and $3 \mathrm{~B}$, we found that both $\mathrm{HE} / \mathrm{M}$ nanoparticles and $\mathrm{DA} / \mathrm{M}$ nanoparticles showed suppressive role in the proliferation of gastric cancer cell lines, which was not as significant as the use of HE/DA/M nanoparticles. HE/DA/M nanoparticles exposure exhibited greater cytotoxicity to SGC7901 and MGC803 cells at the same concentrations of $\mathrm{HE}$ and DA alone. Following, HE/M $(100 \mathrm{ng} / \mathrm{ml})$ nanoparticles, DA/M nanoparticles (100 $\mathrm{ng} / \mathrm{ml})$ and HE/DA/M nanoparticles $(100: 100 \mathrm{ng} / \mathrm{ml})$ were chosen to treat gastric cancer cells. In Figure 3C and 3D, the morphology of gastric cancer cells indicated that administration of HE/DA/M nanoparticles exhibited more effective role in suppressing the growth of gastric cancer cells, which was in line with the results of MTT analysis above. Furthermore, to calculate the cytotoxicity of HE/M, DA/M and HE/DA/M nanoparticles, human normal gastric epithelium cell line (GES1), human normal liver cell line (HL-7702), and rat cardiac muscle cell line (H9C2) were treated to different concentrations of HE, DA or HE/DA nanoparticles as indicated for 24 $\mathrm{h}$, followed by MTT analysis. Following the induction of HE, DA and HE/DA nanoparticles, the cell viability was not significantly changed compared to the Con group in GES1, HL-7702 and H9C2 cells (Figure 3E$3 \mathrm{G})$. Therefore, MTT analysis indicated that HE/DA nanoparticles might be safe for application against human gastric cancer progression.
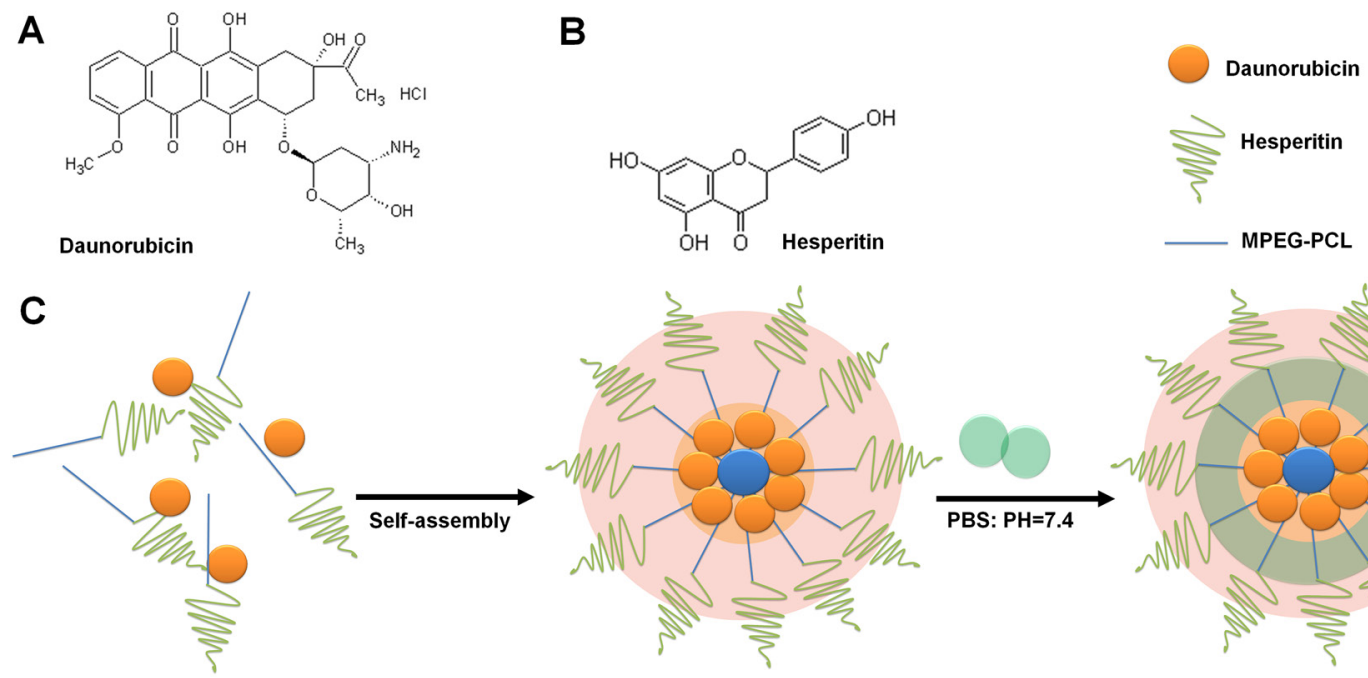

D

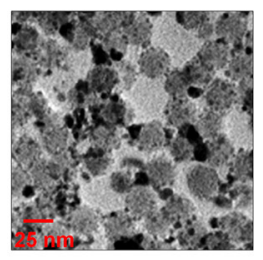

E

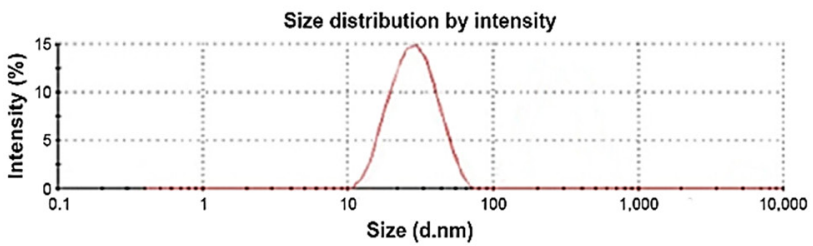

$\mathbf{F}$

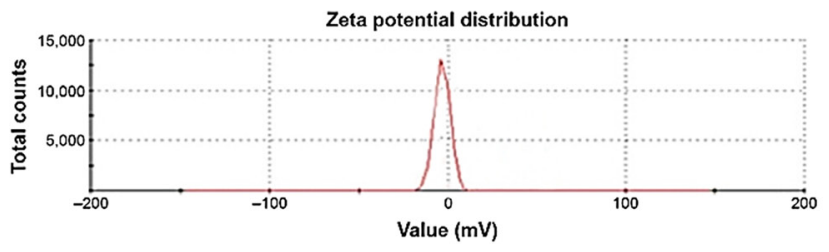

Figure 1: Daunorubicin-Hesperitin-MPEG-PCL (HE/DA/M) nano-micelles are prepared by a self-assembly procedure. (A) The chemical structure of daunorubicin. (B) The chemical structure of hesperitin. (C) The Daunorubicin-Hesperitin-MPEG-PCL (HE/ $\mathrm{DA} / \mathrm{M}$ ) nano-micelles were prepared in a two-step method by self-assembly. DA and HE were co-dissolved in acetone, and then the mixture was added into distilled water for stirring. Following, $1 \mathrm{~mL}$ of $10 \times \mathrm{PBS}(0.1 \mathrm{M}, \mathrm{pH} 7.4)$ was added into $8 \mathrm{~mL}$ HE/MPEG-PCL nano-micelles for complete mixing. Subsequently, $1 \mathrm{~mL}$ of DA solution $(5 \mathrm{mg} / \mathrm{mL})$ was slowly dripped into the mixture under the continuous stirring using a mechanical stirrer. (D) The TEM image of HE/DA/M nano-micelles was exhibited. (E) The size distribution of DA-HE-MPEG-PCL (HE/ DA/M) nano-micelles was shown. (F) Zeta potential distribution of DA-HE-MPEG-PCL (HE/DA/M) nano-micelles was displayed. 


\section{HE/DA/M induces apoptosis in human gastric cancer cells}

In order to explore if apoptosis was involved in the suppression of the growth of gastric cancer cells, flow cytometry analysis was used here. From Figure 4A, more apoptotic cells were observed in HE/DA/M nanoparticles- treated groups, which were comparable to the $\mathrm{HE} / \mathrm{M}$ and DA/M groups, as well as the Con group in both SGC7901 and MGC 803 cells (Figure 4B and 4C). In addition, we also verified the expression of essential signaling proteins related to apoptosis through western blotting analysis. From Figure $4 \mathrm{D}$, the protein expression levels of cleaved Caspase-8 (cleaved Casp-8), cleaved Caspase-9 (cleaved Casp-9),
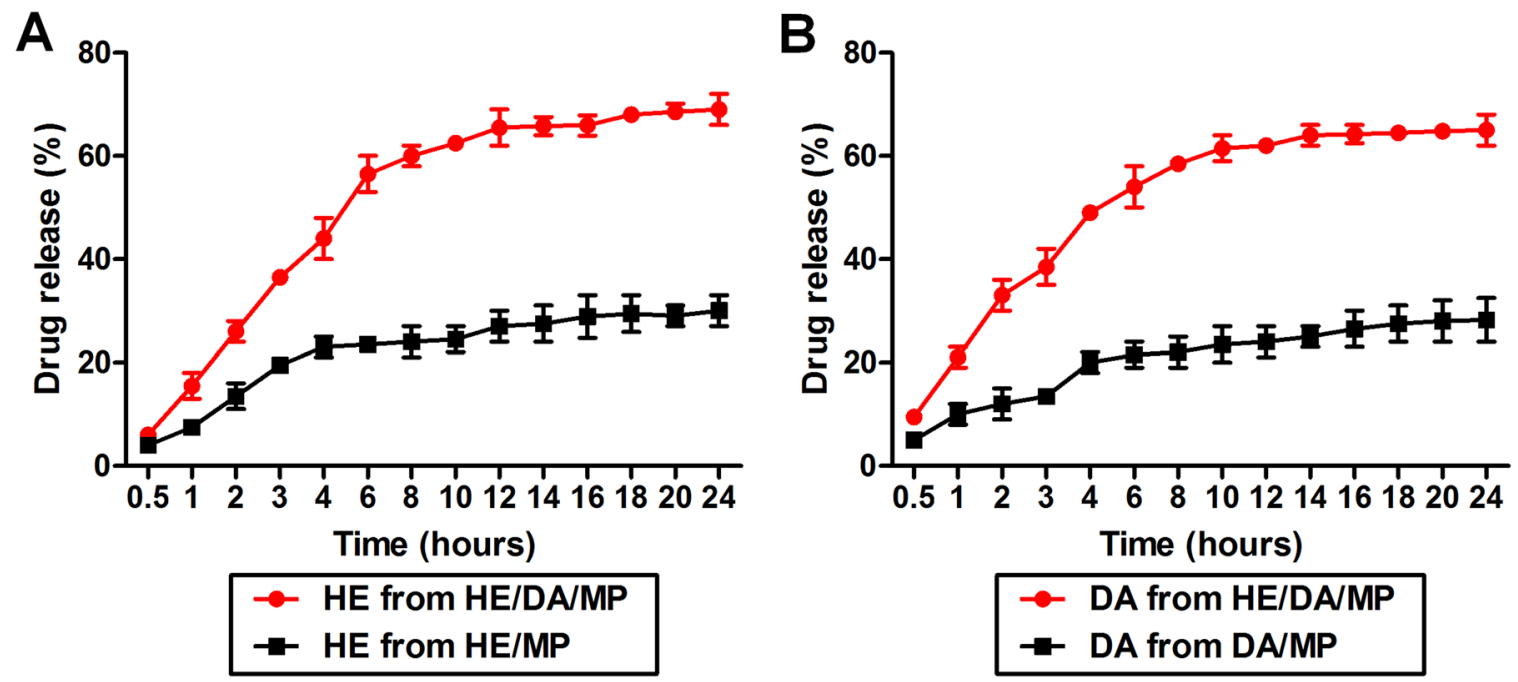

Figure 2: The assessment of drug release in vitro. (A) HE was released from HE/DA/M nano-micelles in vitro. (B) DA was released from $\mathrm{HE} / \mathrm{DA} / \mathrm{M}$ nano-micelles in vitro.
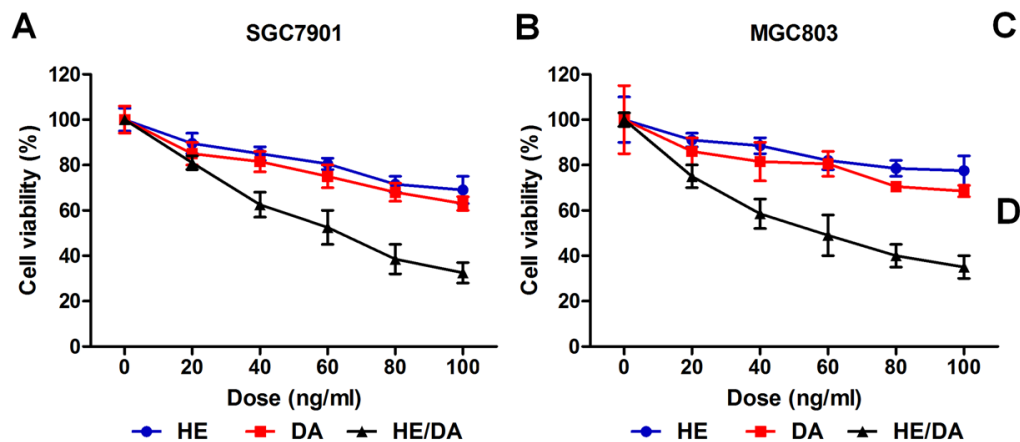

C $\quad$ sGC7901
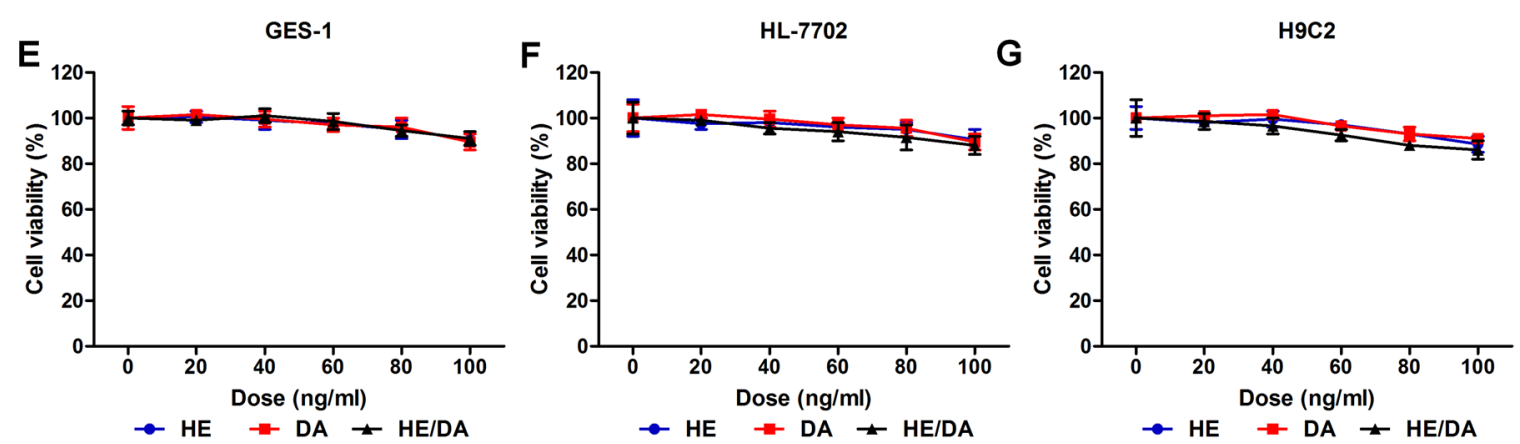

Figure 3: HE/DA/M suppressed the cell viability of gastric cancer cells. Gastric cancer cell lines of (A) SGC7901 and (B) MGC803 were cultured with HE/M, DA/M or the two in combination (the ratio of HE to DA was 1:1.) for $24 \mathrm{~h}$, followed by MTT analysis to evaluate the cell viability. The morphology of (C) SGC7901 and (D) MGC803 cells treated under various conditions as indicated. (E) Human normal gastric epithelium cell line (GES1), (F) human normal liver cell line (HL-7702), and (G) rat cardiac muscle cell line (H9C2) were treated to different concentrations of HE, DA or HE/DA (The ratio of HE to DA was 1:1.) nanoparticles as indicated for $24 \mathrm{~h}$, followed by MTT analysis. 
cleaved Caspase-3 (cleaved Casp-3) and poly (ADP-ribose) polymerase (cleaved PARP) were all remarkably increased after treatment with $\mathrm{HE} / \mathrm{M}(100 \mathrm{ng} / \mathrm{ml})$ nanoparticles, $\mathrm{DA} / \mathrm{M}$ nanoparticles $(100 \mathrm{ng} / \mathrm{ml})$, and especially $\mathrm{HE} /$ DA/M nanoparticles $(100: 100 \mathrm{ng} / \mathrm{ml})$ in gastric cancer cell lines. Next, only HE/DA/M nanoparticles at various concentrations as indicated for $24 \mathrm{~h}$ were used to gastric cancer cells for apoptosis-related signals investigation. The data indicated that HE/DA/M-induced expression of cleaved Casp-8, -9, -3 and PARP was dose-dependently in gastric cancer cell lines (Figure 4E). Further, proliferation-related signals were measured using western blot analysis. PCNA and Cyclin D1, playing an important role in promoting cell proliferation, were dramatically suppressed by HE/DA/M nanoparticles in a dose-dependent manner. In contrast, p21 and p27 were highly induced due to HE/DA/M exposure, which was also in a concentration-dependent manner (Figure 4F and 4G). The cell apoptosis could be induced by both extrinsic and intrinsic signaling pathways. And the growth process was inhibited by HE/DA/M via blocking the proliferative process.

\section{The in vivo pharmacokinetics evaluation of HE/DA/M nanoparticles}

The mean plasma concentration-time curves of $\mathrm{HE} / \mathrm{M}, \mathrm{DA} / \mathrm{M}$ and HE/DA/MP nanoparticles in mice after intravenous administration of $\mathrm{HE} / \mathrm{M}, \mathrm{DA} / \mathrm{M}$ and $\mathrm{HE} / \mathrm{DA} /$ MP nanoparticles were shown in Figure 5A and 5B. HE/ DA-loaded micelles dramatically enhanced the plasma concentration of $\mathrm{HE}$ and DA in comparison to the HE/M and DA/M nanoparticles. The results indicated that HE/DA/ MP nanoparticles could markedly improve the concentration of HE and DA in blood. As shown in Figure 5C and 5D, the ex vivo fluorescent images of excised tumors and organs, isolated from mice treated with HE/DA/MP nanoparticles for 0.5 and 2 hours, indicated that most of the HE/DA/MP nanoparticles accumulated in the tumor tissues, and some were distributed in liver, renal, heart, spleen, as well as the lung. The bio-distribution of $\mathrm{HE}$ and DA was further measured and the results were exhibited in Figure 5E and $5 \mathrm{~F}$, resp n ectively. The quantitative distribution results of $\mathrm{HE}$ and DA in vivo were in line with the qualitative results evidenced by fluorescence images, indicating that $\mathrm{HE} /$ DA/MP nanoparticles mainly accumulated in tumor tissue samples, followed by liver, renal, heart, spleen and lung. In addition, more concentrations of $\mathrm{HE}$ and DA were released from HE/DA/MP than that in the HE/MP and DA/MP groups. Thus, higher accumulation of HE/DA/MP in tumor would be conducive to exhibit better antitumor effects in vivo.

\section{The in vivo biosafety evaluation of $\mathrm{HE} / \mathrm{DA} / \mathrm{M}$ nanoparticles}

C57BL6 mice were administered with HE/MP (5 $\mathrm{mg} / \mathrm{kg}$ ), DA/MP $(5 \mathrm{mg} / \mathrm{kg}$ ) and HE/DA/MP (The ratio of
HE to DA was $1: 1$, at $5 \mathrm{mg} / \mathrm{kg}$.) for consecutive 7 weeks. Next, all mice were sacrificed for isolation of organs, including liver, renal, heart and lung, and collection of blood. The histological examination showed that compared to the Con group in the absence of any treatments, liver, kidney, heart and lung of the drug-treated groups had no appreciable pathological lesion, indicating that there might be none of toxicity of HE/MP, DA/MP and HE/DA/MP (Figure 6A). Following, in order to verify the long-term toxicity of HE/M, DA/M and HE/DA/M nanoparticles, the blood biochemistry indexes, such as AST, ALT, BUN and CREA, were evaluated. ALT and AST levels indicate the liver functions of mice, and BUN and CREA levels suggest the renal function [29,30]. Our data revealed that no significant difference was observed in each index of the treated mice in comparison to the group without any treatments, further confirming that HE/DA/MP might possess no harmful effects on the liver and renal functions (Figure 6B).

\section{The anti-tumor effects of $\mathrm{HE} / \mathrm{DA} / \mathrm{M}$ nanoparticles on SGC7901-bearing mice}

To calculate the anti-cancer effects of HE/DA/MP in vivo, the subcutaneous injection of SGC7901 cells was applied. As shown in Figure 7A, we found that significant anti-cancer ability was observed in HE/M, DA/M, and HE/DA/M nanoparticles groups, which were comparable to the Con group. And of note, HE/DA/M nanoparticles exhibited stronger anti-tumor role in SGC8901-bearing tumor samples compared to the HE/M and DA/M single group. Consistently, the tumor weight and volume in the HE/DA/M nanoparticles group was obviously smaller than that of Con, HE/M and DA/M nanoparticles groups (Figure 7B and 7C). Figure 7D and 7E exhibited the liver weight and body weight of mice from different groups, indicating that there was no alterations among each group, which demonstrated that there might be no severe side effects of HE/M, DA/M and DA/HE/M nanoparticles.

\section{The immunohistochemical (IHC) analysis of HE/ DA/M nanoparticles on tumor tissues}

In order to further calculate the therapeutic efficiency of HE/M, DA/M and DA/HE/M to mice with SGC7901 tumor in vivo, the histological assays of tumors was conducted after 28 days of intravenous administration of drugs. H\&E staining and KI-67 analysis indicated that $\mathrm{HE} / \mathrm{M}, \mathrm{DA} / \mathrm{M}$ and $\mathrm{HE} / \mathrm{DA} / \mathrm{M}$ treatments reduced the progression of tumor tissues, evidenced by reduced number of tumor cells and KI-67 positive levels (Figure $8 \mathrm{~A}$ and $8 \mathrm{~B}$ ). IHC analysis demonstrated the increasing in mean areas which were positively stained for TUNEL and cleaved Caspase-3 in HE/M, DA/M and HE/DA/Mtreated tumor tissue samples, which were comparable to the Con group. And obviously, HE/DA/M-treated groups exhibited higher levels of TUNEL and cleaved Caspase-3 


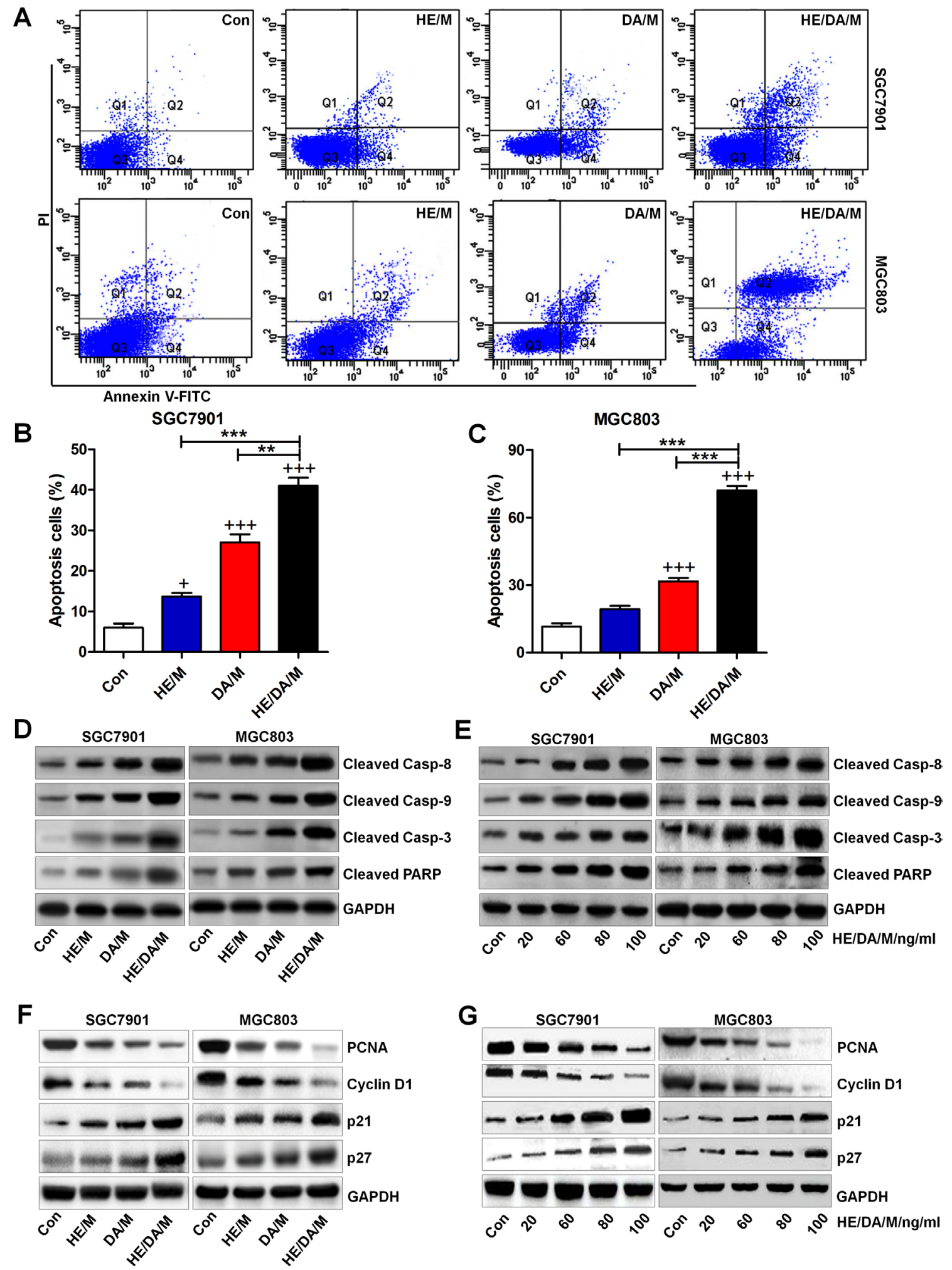

Figure 4: HE/DA/M induces apoptosis in human gastric cancer cells. (A) Gastric cancer cell lines of SGC7901 and MGC803 were treated with HE/M (100 ng/ml), DA/M (100 ng/ml) or the two $(100: 100 \mathrm{ng} / \mathrm{ml})$ in combination for $24 \mathrm{~h}$, and then flow cytometry analysis was used to calculate the apoptosis cells. The percentage of (B) SGC7901 and (C) MGC803 undergoing apoptosis was quantified and exhibited. (D) SGC7901 and MGC803 were exposed to HE/M (100 ng/ml), DA/M (100 ng/ml) or the two (100:100 ng/ml) in combination for $24 \mathrm{~h}$. And, western blot analysis was used to calculate apoptosis-related proteins, including cleaved Caspase-8, $-9,-3$, and PARP. (E-G) SGC7901 and MGC803 cells were cultured with various concentrations of HE/DA/M (0, 20, 60, 80 and 100 ng/ml in 1:1 dilution) for $24 \mathrm{~h}$, followed by PCNA, Cyclin D1, p21 and p27 evaluation via western blot analysis. The data are represented as the mean \pm SEM. ${ }^{+} P<0.05,{ }^{++} P<0.001$ versus the group of Con; ${ }^{* *} P<0.01,{ }^{* * *} P<0.001$ versus the group of HE/DE/M. 
in tumor sections (Figure 8A, 8C and 8D). These data above suggested that HE/DA/M effectively suppressed gastric cancer cells growth in vivo.

\section{DISCUSSION}

Chemotherapy is reported as one of the most effective treatments for tumors [5, 6, 31]. However, anti- cancer drugs administration usually results in side effects, including hair loss, nausea, and vomiting, limiting the dosage and frequency of drugs $[32,33]$. In addition, a variety of drugs, including natural extracts, are restricted for their poor water solubility with low bioavailability $[34,35]$. Hesperitin is reported to possess anti-cancer ability, such as prostate cancer and esophageal cancer $[22$, $36,37]$. Unfortunately, its efficiency was limited due to

A

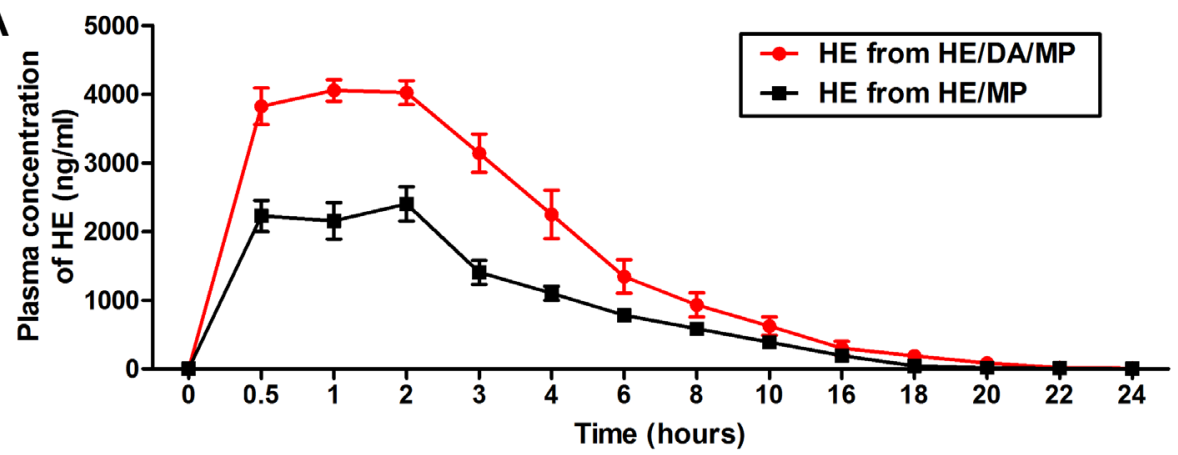

B

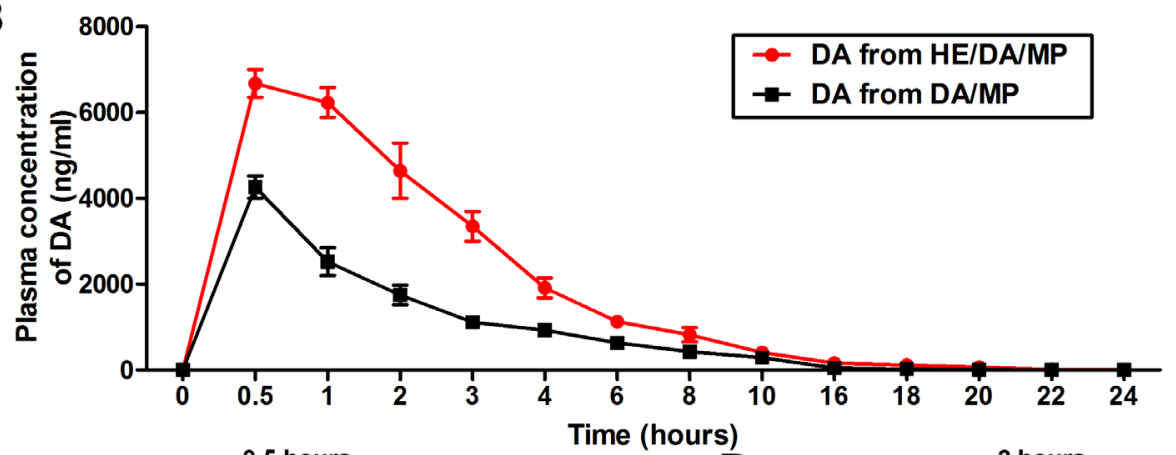

C

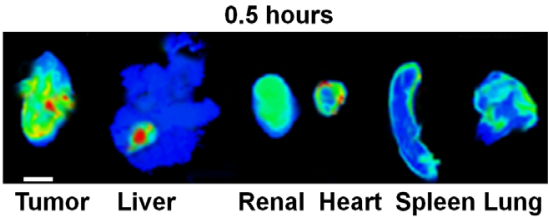

D

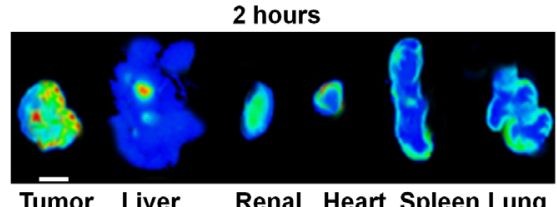

E

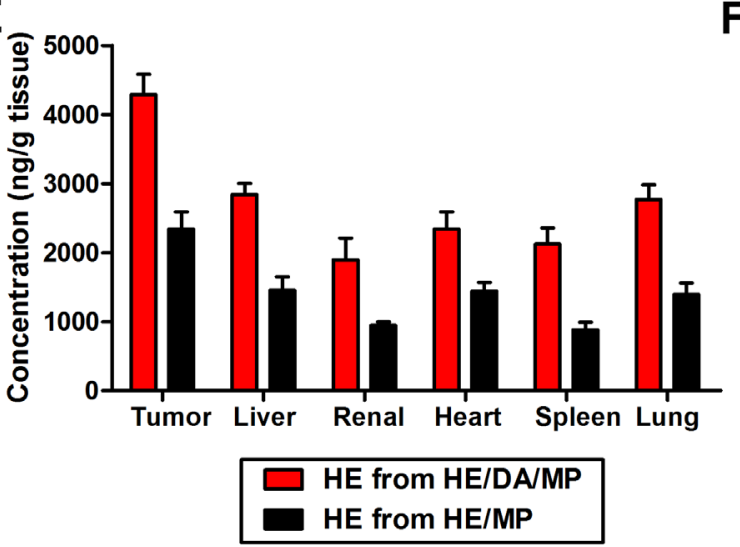

$\mathbf{F}$

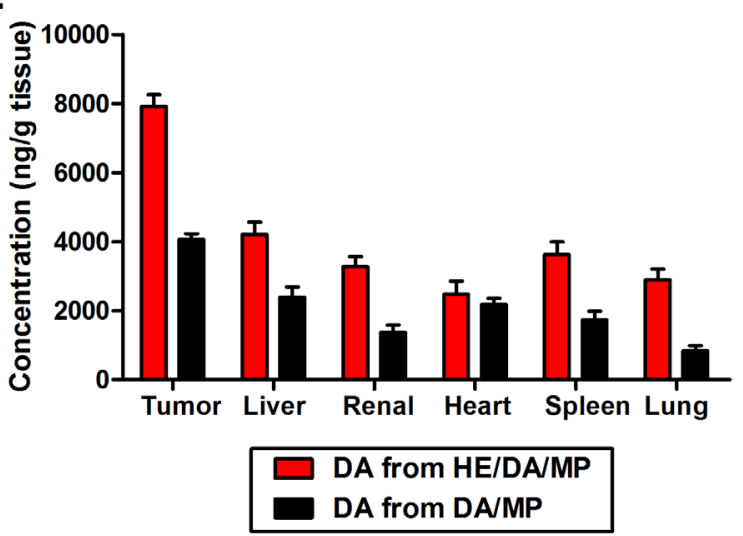

Figure 5: The in vivo pharmacokinetics evaluation of HE/DA/M nanoparticles. The mice were administered with $\mathrm{HE} / \mathrm{M}$ (5 $\mathrm{mg} / \mathrm{kg}$ ), DA/M (5 mg/kg) or the two (ratio of HE to DA, 1:1, $5 \mathrm{mg} / \mathrm{kg}$ ) in combination. Plasma concentration-time curves of (A) HE and (B) DA are assessed and shown. Fluorescent images of tumors and major tissues, including liver, renal, heart, spleen and lung, harvested from SGC7901-bearing mice at (C) 0.5 hours and (D) 2 hours after intravenous administration of the two drugs in combination (ratio of HE to DA, 1:1, $5 \mathrm{mg} / \mathrm{kg}$ ). The scale bar $=5 \mathrm{~mm}$. Quantitative assays of the distribution of (E) HE and (F) DA in SGC7901 tumor-bearing mice at 2 hours after the intravenous administration of HE/DA/M nanoparticles. The data are represented as the mean $\pm \mathrm{SEM}$. 
high hydrophobicity $[20,25,47]$. Daunorubicin is mainly used for prevention of leukemia, breast cancer, and colon cancer $[26,27,38,39]$. Daunorubicin is accompanied with cardiac toxicity, which restrained the dosage that could be used [40]. Application of nanoparticles as carrier systems for chemotherapeutic drugs are accumulating attention for the specificity of nanoparticles for tumor tissues, promoted efficiency, and reduced side effects [41, 42]. The biodegradable nano-carriers have intense potential to deliver two or more drugs. Co-delivery using a single nano-carrier ensures the controlled drug ratios, same drug disposition behavior and hence maximizing the therapeutic efficacy [43-45].

Here in our study, the MPEG-PCL micelles were used to co-deliver $\mathrm{HE}$ and DA, developing an intravenously-injectable formulation. Micelles could be prepared from polyethylene glycol (PEG) and poly ( $\varepsilon$-caprolactone) (PCL), which are biodegradable, and amphiphilic, respectively, providing the hydrophilic and hydrophobic components $[46,47]$. The hydrophobic PCL segments pack together to form the core, functioning as a potential nano-container of hydrophobic drugs, whereas the outer hydrophilic PEG is a stabilizing shell. Therefore, the encapsulation of hydrophobic drugs into the core-shell nanostructure could completely render them dispersible in solution $[48,49]$. The present study was undertaken for co-delivery of HE and DA by using MPEG-PCL as drug delivery carrier for gastric tumor targeting. In our study, the HE/DA/M nano-micelles were prepared through a two-step nano-precipitation method, which was simple to scale up. The MPEG-PCL co-polymer self-assembled into the core-shell structures, encapsulating HE, DA, and HE/DA during the process. Particle size is important parameter for consideration in oral absorption, toxicity and systemic distribution [50]. The HE/DA/M nano-micelles were evidenced as monodisperse, and the average particle size of these particles was about $38 \mathrm{~nm}$.

The therapeutic effects of HE/DA/M nanoparticles were investigated through in vitro and in vivo. The in vitro study for release analysis indicated that HE/DA/M nanomicelles significantly released HE and DA, which were more slowly than that of HE/M and DA/M nanoparticles individually. The combination of the small particle size and slow rate of HE and DA release from HE/DA/M nanomicelles could potentially circulate in organism bodies for a long time after application, contributing to the plasma drug concentrations. in vitro, MTT analysis indicated that HE/ DA/M nano-particles exhibited stronger anti-tumor activity in gastric cancer cells than individual treatment of $\mathrm{HE} / \mathrm{M}$ and DA/M nano-micelles. In addition, HE/DA encapsulated
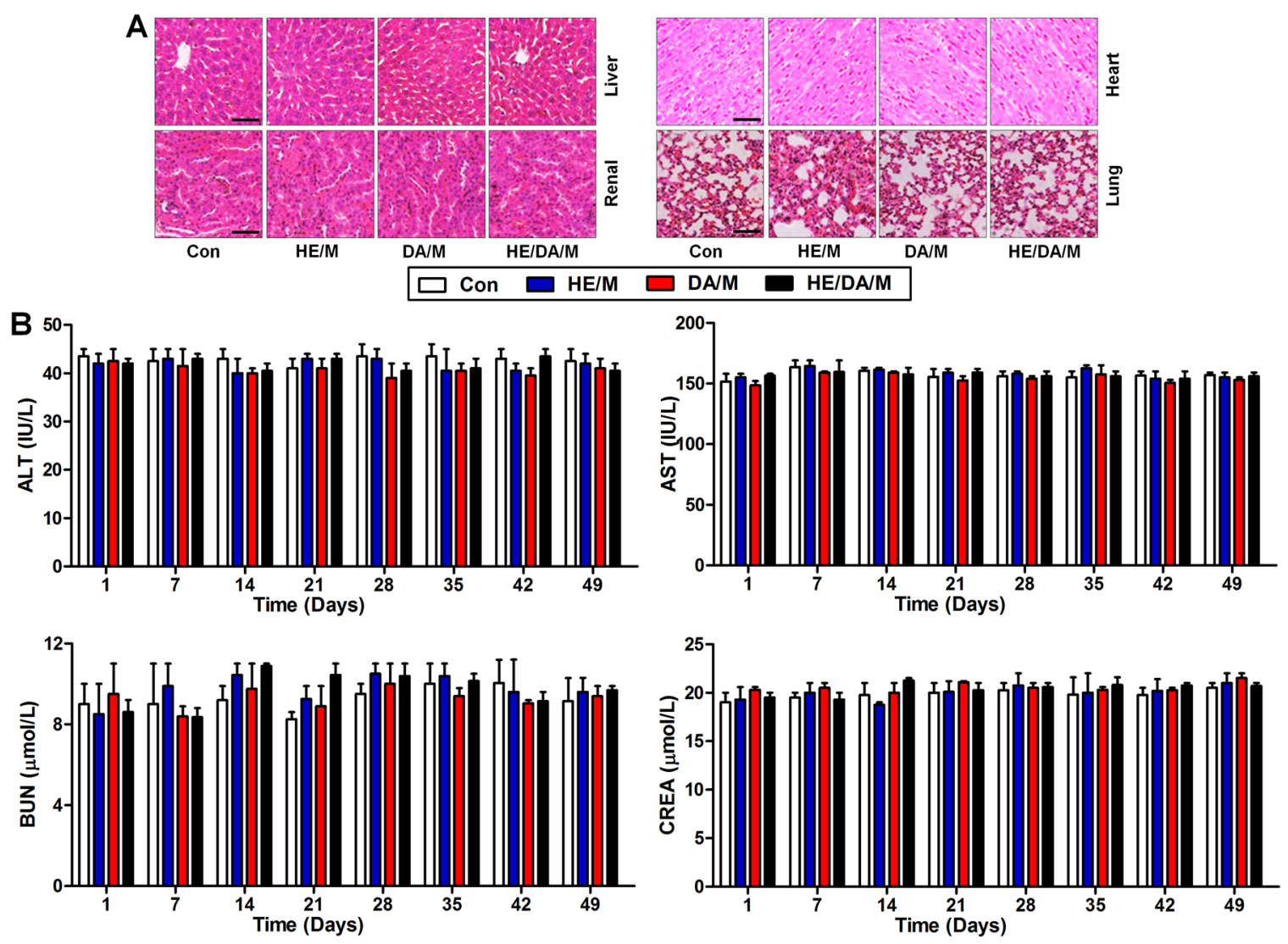

Figure 6: The in vivo biosafety evaluation of HE/DA/M nanoparticles. (A) Pathological lesions in the major organs, including liver, renal, heart and lung, evaluated by H\&E staining, the scale bars present $200 \mu \mathrm{m}$. (B) The blood biochemistry for liver and renal function, evidenced by ALT and AST, as well as BUN and CREB, respectively. The data are represented as the mean $\pm \operatorname{SEM}$. 
A

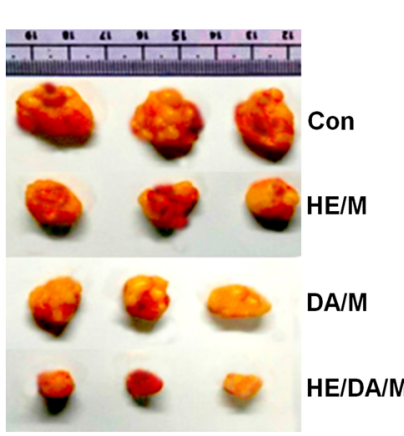

C

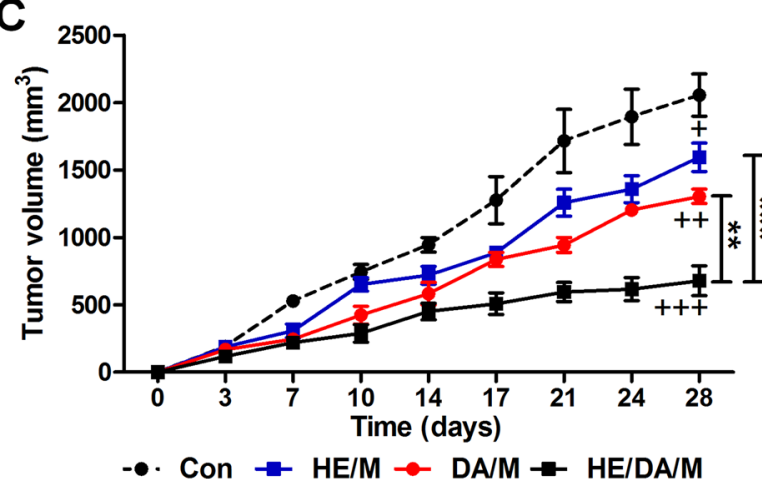

B

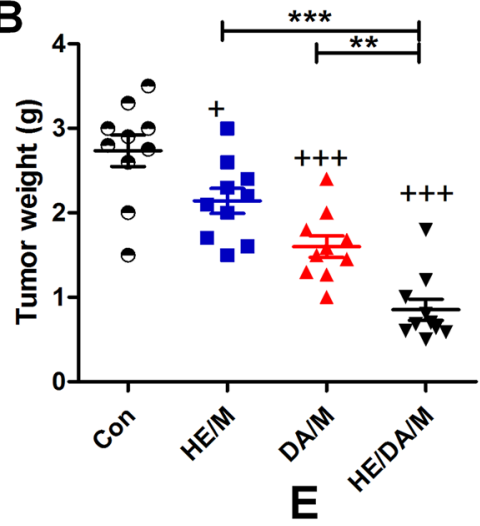

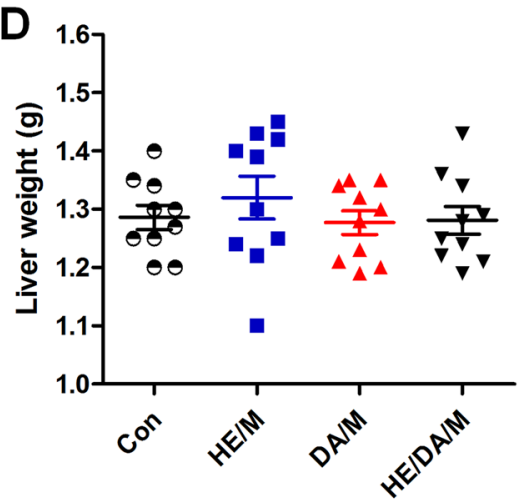

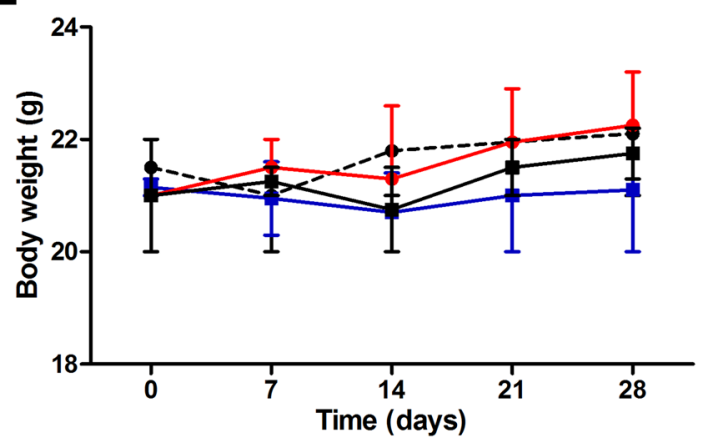

-๑. Con $\rightarrow H E / M \rightarrow D A / M \rightarrow H E / D A / M$

Figure 7: The anti-tumor effects of HE/DA/M nanoparticles on SGC7901-bearing mice. (A) The representative images of excised tumor from the sacrificed mice bearing SGC7901 cells. The changes in (B) tumor weight and (C) tumor volume were measured. (D) The liver weight and (E) body weight of mice were assessed. The data are represented as the mean \pm SEM. ${ }^{+} P<0.05,{ }^{+} P<0.01$, and ${ }^{++} P<0.001$ versus the group of $\mathrm{Con} ;{ }^{* *} P<0.01,{ }^{* * *} P<0.001$ versus the group of HE/DE/M.
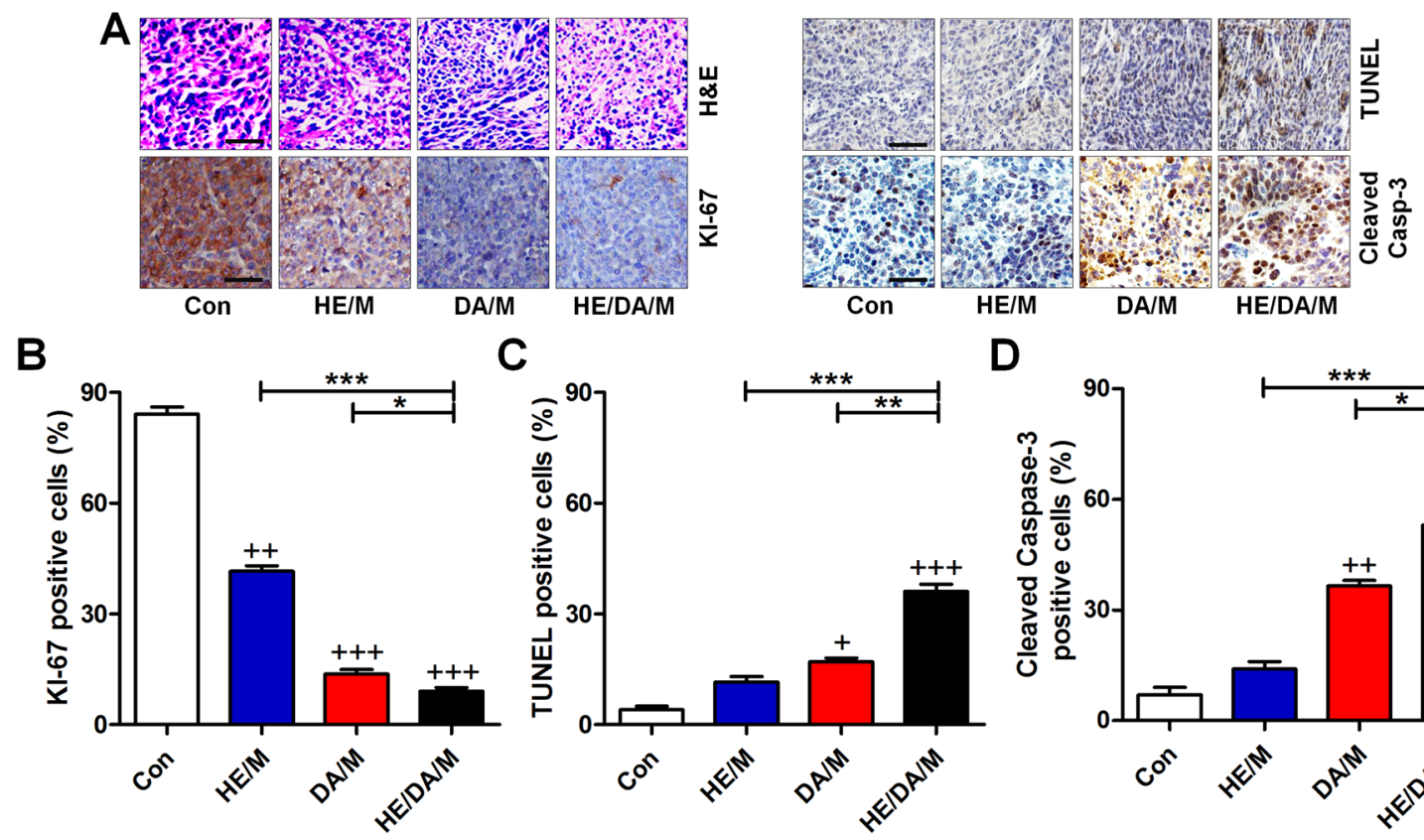

C
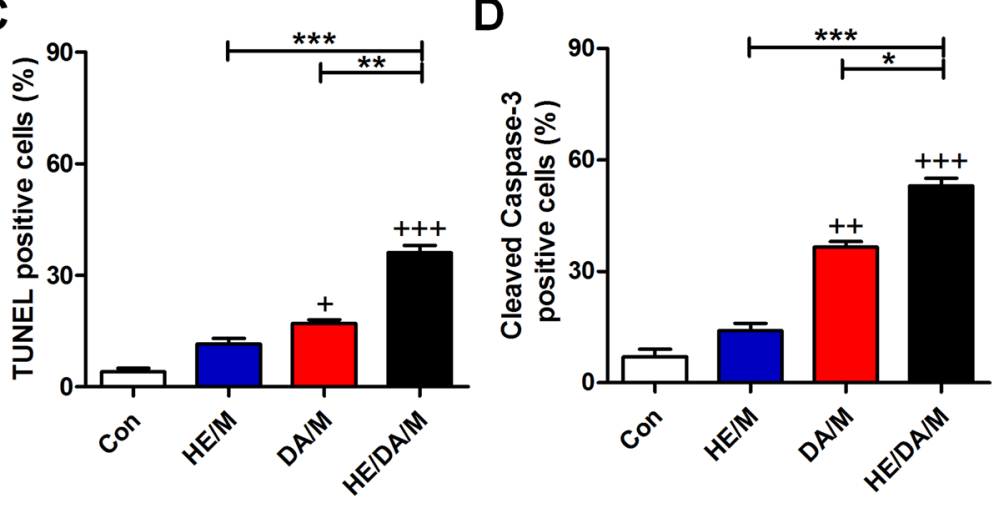

Figure 8: The immunohistochemical (IHC) analysis of HE/DA/M nanoparticles on tumor tissues. (A) H\&E staining of tumor samples were exhibited. The immunohistochemical analysis of KI-67, TUNEL and Cleaved Caspase-3 expressions in tumor tissue samples from mice treated under different conditions as indicated were displayed. (B) KI-67, (C) TUNEL and (D) cleaved Caspase-3 positive levels were quantified following the IHC analysis. The data are represented as the mean \pm SEM. ${ }^{+} P<0.05,{ }^{+} P<0.01,{ }^{++} P<0.001$ versus the group of Con; ${ }^{*} P<0.05,{ }^{* *} P<0.01,{ }^{* * *} P<0.001$ versus the group of HE/DE/M. 
in HE/DA/M nano-micelles was more effective in potentiating gastric cancer cell apoptosis. Importantly, the percentage of apoptotic cells in HE/DA/M nano-micellestreated group was higher than those in HE/M- and DA/ M- treated groups, which was likely due to the stronger synergistic anti-tumor effects of the drugs, the polymer as well as the smaller particle size of nano-micelles. Apoptosis, a canonical pathway allowing cells to undergo a highly regulated form of cell death in response to proapoptotic stimuli, is triggered by multiple signal pathways [51-53]. Recently, a variety of studies have indicated that there are mainly two pathways included in the modulation of apoptosis. The one is extrinsic pathway, including the ligand interaction with their cell surface respective death receptors. The protease Caspase- 8 , Caspase- 3 and other down-streaming Caspases can be activated, resulting in the apoptotic cascade [54]. And the other is intrinsic pathway, which is relied on Caspase-9 cleavage, and has a close relationship with mitochondria [55]. Our finding indicated that HE/DA/M nanoparticles could significantly induce the cleavage of Caspase-8, Caspase-9, Caspase-3 and PARP, indicating a stronger effect of $\mathrm{HE} / \mathrm{DA} / \mathrm{M}$ on apoptosis induction than HE/M and DA/M nano-micelles. Moreover, the in vivo study confirmed that the application of $\mathrm{HE} /$ DA/M nanoparticles was more effective in suppressing gastric tumor growth, which was comparable to the HE/M and DA/M individual treatment in a subcutaneous SGC8901 tumor model, further proved by H\&E staining, TUNEL and cleaved Caspase- 3 positive areas in tumor tissue samples. Proliferative activity of a tumor defines its aggression, and is an indicator of the prognosis [56]. A number of indicators of proliferative activity are known. The greatest interest in recent years has focused on the biomarker, KI-67, as an index of proliferative activity. Thus, KI-67 staining in our study suggested that HE/DA/M nanoparticles exhibited greater anti-proliferative effects against gastric tumor progression $[57,58]$. In addition, PCNA plays an important role in the initiation of cell proliferation. This molecule is observed in proliferating cells or cells that demonstrate a proliferating tendency. Therefore, PCNA reflects the proliferating condition of the whole cell population [59, 60]. Cyclin D1 is a member of a family of three closely associated D-type Cyclins, D1, D2 and D3, which promote progression through the G1-S phase of the cell cycle [61]. High levels of Cyclin D1 have been detected in numerous cancer cell lines through DNA amplification and/or Cyclin D1 over-expression $[62,63]$. Here in our study, we found that compared to $\mathrm{HE} / \mathrm{M}$ and $\mathrm{DA} / \mathrm{M}$ nano-micelles treatment, HE/DA/M exhibited stronger inhibitory role in PCNA and Cyclin D1 expression, contributing to the suppression of gastric cancer cell proliferation. p21 and p27 are important cyclin-dependent kinase inhibitors, playing an essential role in the induction of cell cycle arrest, suppressing cancer cell proliferation $[64,65]$. Consistently, in our study, HE/DA/M greatly improved p21 and p27 expressions.

Moreover, our HE/DA/M nano-micelles showed stronger anti-cancer effects than DA/M nano-micelles or
HE/M nano-micelles in vivo. And the ex vivo fluorescent images of excised tumors and organs confirmed the anticancer effects of HE/DA/M nano-micelles. Most of the drug micelles accumulated in the tumor, and some were distributed in liver, renal, heart, spleen and lung. The findings suggested that HE/DA/M nano-micelles showed specificity to be accumulated in tumor tissues. Additionally, the toxicity of $\mathrm{HE} / \mathrm{DA} / \mathrm{M}$ formulation in vivo was investigated through assessing essential hepatic and renal health indexes $[26,30$, $66,67]$. AST, ALT, BUN and CREA contents in mice with treatment of $\mathrm{HE} / \mathrm{DA} / \mathrm{M}$ nano-micelles were similar to that in the Con group, indicating that HE/DA/M nano-micelles caused no severe hepatic and kidney toxicity. Further, the histological analysis of major organs of liver, renal, heart and lung suggested that no obvious pathological damage was induced by HE/DA/M nanoparticles.

In summary, here in our study, the intravenouslyinjectable HE/DA/M nano-micelles were successfully prepared, exhibiting promoted anti-cancer ability in gastric cancer, which was attributed to its direct cellular cytotoxicity, enhanced effects on apoptosis induction, slower release and tumor targeting capacity. And the excellent anti-cancer effects were along with low toxicity both in vitro and in vivo. The data indicated that HE/DA/M nano-micelles possess potential value to prevent human gastric cancer.

\section{MATERIALS AND METHODS}

\section{Materials}

Hesperitin was purchased from Sigma (St. Louis, MO, USA). Daunorubicin was purchased from Santa Cruz (Dallas, TX, USA). 3-(4,5-dimethyl-2-thiazolyl)-2,5diphenyl-2H-tetrazolium bromide (MTT) were purchased from Beyotime Institute of Biotechnology (Shanghai, China). Aspartate aminotransferase (AST) Assay Kit, Alanine aminotransferase (ALT) Assay Kit, Urea (BUN) Assay Kit and Creatinine (Cr) Assay kit were purchased from Nanjing Jiancheng Bioengineering Institute (Nanjing, China). Annexin V-FITC/PI Detection kit was obtained from keyGEN Biotech (Shanghai, China). The enhanced chemiluminescence (ECL) and bicinchoninic acid (BCA) were purchased from Thermo Fisher Scientific (San Diego, CA, USA).

\section{Preparation and characterization of daunorubicin-hesperitin-MPEG-PCL (HE/ DA/M) nano-micelles}

MPEG-PCL copolymer with a designed molecular weight of $14000 \mathrm{~g} / \mathrm{mol}$ was synthesized via ring-opening polymerization. Predetermined amounts of MPEG ( $M n=2000$, Jenkem Technology Co, Ltd, Beijing, China) and $\varepsilon$-caprolactone (Jenkem Technology Co, Ltd) were put in a dried three-necked flask containing stannous octoate dissolved in anhydrous toluene solution. The reaction 
system was refluxed under dry nitrogen atmosphere at $130^{\circ} \mathrm{C}$ for $24 \mathrm{~h}$. The crude copolymer was dissolved in dichloromethane followed by evaporation of the toluene solution. The solution was then added to cold diethyl ether to eliminate the unreacted MPEG. Subsequently, the resultant block copolymer was dried to a constant weight in a vacuum oven at room temperature and stored in the air-tight bags pending characterization. The MPEG-PCL formation was determined using proton nuclear magnetic resonance $\left({ }^{1} \mathrm{H}\right.$ NMR) and gel permeation chromatography (GPC). ${ }^{1} \mathrm{H}$ NMR spectrum was obtained with a Bruker AVANCE 600 spectrometer (Bruker, Germany) with deuterated chloroform as the solvent. Additionally, the number average molecular weights, the weight average molecular weight and the polydispersity index were confirmed through a gel permeation chromatography (GPC) system equipped with a refractive index detector and a Styragel HR column. HPLCgrade tetrahydrofuran was introduced as the eluent at a flow rate $1.0 \mathrm{~mL} / \mathrm{min}$. The calibration curve was generated using polystyrene standards with a molecular weight range from 900 to $30000 \mathrm{~g} / \mathrm{mol} .5 \mathrm{mg} \mathrm{HE}$ and $90 \mathrm{mg}$ MPEG-PCL copolymer were co-dissolved in acetone $(2 \mathrm{ml})$ to form an organic phase. Then, the mixture was added into water with mechanical stirring moderately. Along with the diffusion of acetone into water, the HE and amphiphilic MPEG-PCL were self-assembled into core-shell structured HE/MPEGPCL nano-micelles. Finally, the mixture was evaporated at $55^{\circ} \mathrm{C}$ using a rotary evaporator under the reduced pressure to diminish acetone. Next, $1 \mathrm{~mL}$ phosphate-buffered saline (PBS, 10×, 0.1 M, pH 7.4) was added into $8 \mathrm{ml} \mathrm{HE/MPEG-}$ PCL nano-micelles and completely mixed. And $1 \mathrm{~mL}$ DA solution $(5 \mathrm{mg} / \mathrm{ml})$ was slowly dripped into the mixture with continuous stirring. The HE/DA/M nano-micelles were prepared. The resulting HE/DA/M nano-micelle solution was filtered through a $200 \mathrm{~nm}$ syringe filter (Whatman Inc., USA) to remove the bacteria and insoluble drugs. The filtered HE/DA/M nano-micelles were then lyophilized and stored at $4{ }^{\circ} \mathrm{C}$ for further exploration. The HE/MPEG-PCL (HE/M), and DA/MPEG-PCL (DA/M) micelle formulations were prepared using the same method, but in the absence of HE or DA in the mixtures.

The distribution of nanoparticle size and the zeta potential of prepared HE/DA/M nano-micelles were calculated through dynamic light scattering (DLS) using a Zetasizer Nano-ZS instrument (Malvern Instruments, UK). During the measuring process, the temperature was maintained at $25^{\circ} \mathrm{C}$. Size is represented as the mean value of 20 runs with triplicate assessments for each run. The morphology characteristics of HE/DA/M nano-micelles were observed with a transmission electron microscope (TEM) (Hitachi, Tokyo, Japan). The diluted micelles were placed on a copper grid, negatively stained with phosphotungstic acid (2\%) and dried at room temperature before TEM observation.

\section{Cell culture in vitro}

Human gastric cancer cell lines of SGC7901 and MGC803 were obtained from American Type Culture Collection (ATCC, Manassas, VA, USA) Human normal gastric epithelium cell line (GES1), human normal liver cell line (HL-7702), and rat cardiac muscle cell line (H9C2) were purchased from the Cell Bank of the Type Culture Collection of the Chinese Academy of Sciences (Shanghai, China). And all cells were maintained in RPMI-1640 medium (Gibco, Grand Island, NY, USA) with $10 \%$ fetal bovine serum (FBS, Hyclone, Thermo Scientific, USA) in a humidified $\mathrm{CO}_{2}$ incubator under 5\% $\mathrm{CO}_{2}$. The cells were harvested in a $0.025 \%$ trypsin-EDTA (Gibco) with phosphate buffered saline solution, plated at the required cell number, and allowed to adhere before drug treatment. The cells were exposed to different doses of drugs for study.

\section{In vitro cytotoxicity}

MTT was used to calculate cell viability. $2 \times 10^{4}$ cells/well were seeded on 96-well plates and incubated at $37^{\circ} \mathrm{C}$ overnight under an atmosphere of $95 \%$ air and $5 \%$ $\mathrm{CO}_{2}$, and then treated with various concentration of $\mathrm{HE} / \mathrm{M}$, GA/M and HE/DA/M (0, 20, 40, 60, 80 and $100 \mathrm{ng} / \mathrm{ml})$ for $24 \mathrm{~h}$. MTT solution $(300 \mu \mathrm{L} /$ well $)$ was added after incubation. Following incubation at $37^{\circ} \mathrm{C}$ for an additional $4 \mathrm{~h}$, the supernatants were removed and $200 \mu \mathrm{l}$ dimethyl sulfoxide (DMSO, Sigma-Aldrich Chemical Co., USA) was added into each well to dissolve the formazan crystals. The 96-well plates were then placed in a microplate reader (Bio-Tek, USA) to assess the absorbance at $490 \mathrm{~nm}$. Each test performed in triplicate.

\section{Drug release in vitro}

HE/DA/M (500 ul) nano-micelle solution was put into a dialysis bag, and HE/M (500 ul) nano-micelles and DA/M (500 ul) nano-micelles were applied as the controls. The dialysis tubes were then incubated in pre-warmed PBS (30 mL, pH 7.4) supplemented with $10 \% \mathrm{FBS}$ at $37^{\circ} \mathrm{C}$. Next, the incubation medium was replaced with fresh medium at the predetermined time points. The drugs that released into the incubation medium were tested by high pressure liquid chromatography (HPLC). The experiment was independently repeated three times.

\section{Flow cytometry}

The treated gastric cancer cells were harvested in PBS. Then, the cells were incubated with annexin V-FITC and PI for $15 \mathrm{~min}$ at room temperature in a darkroom. The stained cells were then analyzed using flow cytometry (BD Pharmingen, USA). 


\section{Western blot analysis}

Gastric cancer cells after different treatments were harvested and washed with chilled PBS. The cells and gastric tumor tissues were lysed in $50 \mathrm{mM}$ Tris-Cl (pH 7.5) supplemented with $0.5 \%$ deoxycholic acid, $150 \mathrm{mM} \mathrm{NaCl}, 0.1 \%$ SDS, $1 \% \mathrm{NP}-40$, and a protease inhibitor (Sigma Aldrich) on ice for 10 min to yield a homogenate. Then, the final supernatants were obtained by centrifugation at $14,000 \times \mathrm{g}$ for $20 \mathrm{~min}$ at $4^{\circ} \mathrm{C}$. Protein concentration was determined using BCA protein assay kit with bovine serum albumin as a standard. Sampleloading buffer was added, the mixture was boiled for 5 min. And the total protein extract are used for Western blot analysis. $40 \mu \mathrm{g}$ of total protein was loaded and proteins were separated using $10 \%$ sodium dodecyl sulfate-polyacrylamide gel electrophoresis (SDS-PAGE) and electrophoretically transferred to the polyvinylidene difluoride membranes (PVDF, Millipore, USA). The membranes were then blocked with $5 \%$ skim milk Tris buffered saline with $0.1 \%$ Tween 20 (TBST), washed, and then incubated with primary antibody overnight at $4^{\circ} \mathrm{C}$. The primary antibodies were shown as followings. The membrane was then washed with TBST for three times, followed by incubation with a horseradish peroxidase (HRP)-conjugated secondary antibody (Amersham Biosciences) at room temperature for $2 \mathrm{~h}$. Following another round of washing with TBST, the membrane was then developed using ECL, and exposed to Kodak (Eastman Kodak Company, USA) X-ray film. Every protein expression levels will be defined as grey value using ImageJ 1.38 software (National Institutes of Health, USA) and standardized to housekeeping gene of GAPDH and expressed as a fold of control. All experiments were performed in triplicate and done three times independently. The primary antibodies for GAPDH (sc-293335, 1:200, Santa Cruz Biotechnology, USA), Caspase-8 (ab25901, 1:1000, Abcam, USA), Caspase-9 (ab2324, 1:1000, Abcam, USA), PCNA (ab18197, 1:1000, Abcam, USA), Cyclin D1 (ab61758, 1:1000, Abcam, USA), p21 (ab86696, 1:1000, Abcam, USA), p27 (ab212252, 1:1000, Abcam, USA), Caspase-3 (ab2302, 1:1000, Abcam, USA), and PARP (ab4830, 1:1000, Abcam, USA) were employed.

\section{Pharmacokinetics analysis in vivo}

40 male C57BL6 mice (18-22 g, 6-8 weeks old) were randomly dividedinto four groups $(\mathrm{n}=10$ in each). The mice were fasted for 12 hours with free access to water before dosing. Saline, HE/M (5 mg/kg), DA/M (5 $\mathrm{mg} / \mathrm{kg}$ ) and HE/DA/M (The ratio of HE to DA was $1: 1$ at $5: 5 \mathrm{mg} / \mathrm{kg}$.) were injected into the mice by the tail vein. At the end of the experiment, the blood samples were collected through puncturing the reto-orbital sinus and subsequently were centrifuged at $3,000 \times \mathrm{g}$ for 15 min to obtain serum, followed by detection of liquid chromatography-tandem mass spectrometry (LC-MS/MS) after precipitation with methanol.

\section{Assessment of anti-cancer effects in vivo}

40 male, 5 weeks old, 15-18 g, BALB/c-nu mice were injected with SGC7901 cells $\left(1 \times 10^{6}\right)$ subcutaneously in the left flank of mice, purchased from the Animal experiment center of Hunan province (Changsha, Hunan PR, China). Mouse care and usage were performed according to the ethical guidelines of Xiangya Hospital, Central South University (Changsha, China). All protocols were in accordance with the Regulations of Experimental Animal Administration issued by the Ministry of Science and Technology of the People's Republic of China. All mice were performed to adjust the environment for 7 days previous to the experiments. The mice were raised in air-conditioned pathogen-free rooms $\left(25 \pm 2{ }^{\circ} \mathrm{C}, 50 \pm 10 \%\right.$ humidity $)$ under controlled lighting (12 h light/day) and fed with water and standard laboratory food. When the tumors were visible, the mice were randomly divided into four groups (10 mice per group). The control group received the vehicle (PBS) injection, and the treatment group was administered with HE/M (5 mg/kg), DA/M $(5 \mathrm{mg} / \mathrm{kg})$ and HE/DA/M (The ratio of HE to DA was $1: 1$ at $5: 5 \mathrm{mg} /$ kg.) through tail vein injection [68-70]. When the tumor volume reached to $50 \mathrm{~mm}^{3}$, the administration of vehicle or drugs was started to animals daily. 28 days later, all mice were sacrificed, and tumors were excised and measured. The tumor tissues were fixed in $10 \%$ formalin. After embedding in paraffin, immunohistochemical analysis was performed.

\section{Measurement of plasma biochemistry indicators}

180 male, 5 weeks old, 15-18 g, BALB/c-nu mice were injected with SGC7901 cells $\left(1 \times 10^{6}\right)$ subcutaneously in the left flank of mice. All mice were randomly divided into 4 groups ( $\mathrm{n}=45$ per group) as followings. When the tumor volume reached to $100 \mathrm{~mm}^{3}$, the administration of vehicle, HE/M (5 mg/kg), DA/M (5 mg/kg) and HE/DA/M was started to animals each day. The side effects of HE/ DA/M nano-micelles in vivo were measured. Briefly, after the drug administration for 1, 7, 14, 21, 28, 35, 42 and 49 days ( $\mathrm{n}=6$ in each group), the blood of each mouse was extracted through eyeballs and the serum was separated by centrifuge at $3,000 \times \mathrm{g}$ for $15 \mathrm{~min}$. Then, the activities of ALT, AST, BUN and CREA in serum were evaluated following the manufacturer's protocol to calculate the organ toxicity. At the end of the experiment, all rest of mice were sacrificed, and the liver, renal, heart and lung tissues were excised, weighed, and fixed in $10 \%$ formalin for histology analysis. 


\section{Tumor-targeting ability in vivo}

24 male, 5 weeks old, 15-18 g, BALB/c-nu mice were injected with SGC7901 cells $\left(1 \times 10^{6}\right)$ subcutaneously in the left flank of mice, purchased from the Animal experiment center of Hunan province (Changsha, Hunan PR, China). When the tumor volume reached to 150 $\mathrm{mm}^{3}$, the administration of vehicle, HE/M $(5 \mathrm{mg} / \mathrm{kg})$, $\mathrm{DA} / \mathrm{M}(5 \mathrm{mg} / \mathrm{kg})$ and HE/DA $/ \mathrm{M}(5 \mathrm{mg} / \mathrm{kg})$ was started to animals daily. Following, at 0.5 hours and 2 hours post-administration, the mice ( $\mathrm{n}=6$ in each group) were sacrificed. The tumor, liver, heart, spleen, kidney, and lung were excised, rinsed with saline, and then imaged with Maestro Imaging System (Caliper, Hopkinton, MA, USA) in vivo imaging system. For quantification analysis, after 2 hours of administration of saline, HE/M, DA/M, and $\mathrm{HE} / \mathrm{DA} / \mathrm{M}$, the tissue samples including tumor, liver, kidney, heart, spleen, and lung were excised, weighed, homogenized with methanol, and then quantified using LC-MS/MS.

\section{Immunohistochemical analysis}

Formalin-fixed tumor tissue samples were embedded in $4 \%$ paraffin and thenthe paraffin-embedded specimens were cut into serial sections (3-um thickness). Primary tumors, liver, heart, lung, and renal sections were stained with hematoxylin and erosion (H\&E) and tumor specimens were immunostained with KI-67 (Abcam, 1:500), and cleaved Caspase-3 (Abcam, 1:500). In brief, Tumor tissues were deparaffinized in xylene, which was followed by hydration using graded alcohol, and then treated with $3 \% \mathrm{H}_{2} \mathrm{O}_{2}$ for $15 \mathrm{~min}$. The boiling sodium citrate buffer was applied for antigen retrieval. Next, tissue sections were incubated with $10 \%$ normal goat serum for $15 \mathrm{~min}$, and then incubated with primary antibodies of KI-67, and Caspase- 3 at $4^{\circ} \mathrm{C}$ overnight. And then, the slides were rinsed with $\mathrm{PBS}$ for three times, and incubated with secondary antibody at $37^{\circ} \mathrm{C}$ for 30 min. 3,3'-diaminobenzidine (DAB) was used for the staining of nuclear. And hematoxylin (Sigma Aldrich) was added for the background counterstaining. Images were captured using a microscopy (Olympus, Japan). The apoptosis of gastric tumor tissues was evaluated using TUNEL assay with the In situ Apoptosis Detection Kit (Abcam) according to the manufacture's protocol. After deparaffinization and hydration, tumor tissue sections were washed with PBS twice and then incubated with proteinase $\mathrm{K}(20 \mu \mathrm{g} / \mathrm{ml}$, Abcam $)$ for $25 \mathrm{~min}$ at $37^{\circ} \mathrm{C}$, followed by washes with PBS. Then, all sections were incubated with TUNEL mixture. Finally, the tissue sections were observed with a microscopy (Olympus, Japan).

\section{Statistical analysis}

Experiments were performed in triplicate and analyzed using GraphPad Prism ${ }^{\circledR}$ version 5.03 software.
Results are expressed as mean \pm standard error (SEM). Statistical analysis was performed through one-way analysis of variance with least significant difference posthoc tests to identify differences between mean values of different groups. $\mathrm{P}<0.05$ was considered as statistical significant.

\section{CONFLICTS OF INTEREST}

The authors declare no competing financial interests.

\section{FOUNDATION}

\author{
1. School Enterprise Cooperation Project.
}

\section{REFERENCES}

1. Wu Z, Li Z, Ji J. Morbidity and mortality of cytoreductive surgery with hyperthermic intraperitoneal chemotherapy in advanced gastric cancer. Transl Gastroenterol Hepatol. 2016; 1:63.

2. Chen Y, Zhang S, Wang Q, Zhang XB. Tumor-recruited M2 macrophages promote gastric and breast cancer metastasis via M2 macrophage-secreted CHI3L1 protein. J Hematol Oncol. 2017; 10:36.

3. Yamaguchi K, Yoshida K, Tanaka Y, Matsuhashi N, Tanahashi T, Takahashi T. Conversion therapy for stage IV gastric cancer - the present and future. Transl Gastroenterol Hepatol. 2016; 1:50.

4. Hsu JT, Yeh TS, Jan YY. Survival impact of the number of lymph node dissection on stage I-III node-negative gastric cancer. Transl Gastroenterol Hepatol. 2016; 1:9.

5. Yin S, Li Z, Huang J, Miao Z, Zhang J, Lu C, Xu H, Xu $H$. Prognostic value and clinicopathological significance of proliferating cell nuclear antigen expression in gastric cancer: a systematic review and meta-analysis. Onco Targets Ther. 2017; 10:319.

6. He Q, Gao J, Ge S, Wang T, Li Y, Peng Z, Li Y, Shen L. Axitinib alone or in combination with chemotherapeutic drugs exerts potent antitumor activity against human gastric cancer cells in vitro and in vivo. J Cancer Res Clin Oncol. 2014; 140:1575-1583.

7. Zhao W, Li L, Liu J, Chen R, Chang S, Qiu G, He S, Wang Z, Wang J, Che X, Wang S. The impact of insulin on chemotherapeutic sensitivity to 5 -fluorouracil in gastric cancer cell lines SGC7901, MKN45 and MKN28. J Exp Clin Cancer Res. 2015; 34:64.

8. Salem A, Noaman E, Badawi A, Badawi A, Mostafa N. Crystal structure and chemotherapeutic efficacy of the novel compound, gallium tetrachloride betaine, against breast cancer using nanotechnology. Tumour Biol. 2016; 37:11025-11038.

9. da Silva PB, de Freitas ES, Bernegossi J, Gonçalez ML, Sato MR, Leite CQ, Pavan FR, Chorilli M. 
Nanotechnology-based drug delivery systems for treatment of tuberculosis: a review. J Biomed Nanotechnol. 2016; $12: 241-260$

10. Jahangirian $\mathrm{H}$, Lemraski EG, Webster TJ, Rafieemoghaddam R, Abdollahi Y. A review of drug delivery systems based on nanotechnology and green chemistry: green nanomedicine. Int J Nanomedicine. 2017; 12:2957.

11. Sun M, Su X, Ding B, He X, Liu X, Yu A, Lou H, Zhai G. Advances in nanotechnology-based delivery systems for curcumin. Nanomedicine (Lond). 2012; 7:1085-1100.

12. Romana B, Batger M, Prestidge AC, Colombo G, Sonvico F. Expanding the therapeutic potential of statins by means of nanotechnology enabled drug delivery systems. Curr Top Med Chem. 2014; 14:1182-1193.

13. Calixto GM, Bernegossi J, de Freitas LM, Fontana CR, Chorilli M. Nanotechnology-based drug delivery systems for photodynamic therapy of cancer: a review. Molecules. 2016; $21: 342$.

14. Pidaparthi K, Suares D. Comparison of nanoemulsion and aqueous micelle systems of Paliperidone for intranasal delivery. AAPS PharmSciTech. 2017; 18:1710-1719.

15. İşoğlu İA, Özsoy Y, İşoğlu SD. Advances in micelle-based drug delivery: cross-linked systems. Curr Top Med Chem. 2016; 17:1469-1489.

16. Wang YJ, Chen LJ, Tan LW, Zhao Q, Luo F, Quan Y, Zhi W, Qian Y. PEG-PCL based micelle hydrogels as oral docetaxel delivery systems for breast cancer therapy. Biomaterials. 2014; 35:6972-6985.

17. Zhang R, Su S, Hu K, Shao L, Deng X, Sheng W, Wu Y. Smartmicelle@polydopamine core-shell nanoparticles for highly effective chemo-photothermal combination therapy. Nanoscale. 2015; 7:19722-19731.

18. Chen CY, Syu CK, Lin HC. A stimulated mixed micelle system for in vitro study on chemo-photodynamic therapy. Macromol Biosci. 2016; 16:188-197.

19. Carballo-Villalobos AI, González-Trujano ME, AlvaradoVázquez N, López-Muñoz FJ. Pro-inflammatory cytokines involvement in the hesperidin antihyperalgesic effects at peripheral and central levels in a neuropathic pain model. Inflammopharmacology. 2017; 25:265-269.

20. Pérez-Vargas JE, Zarco N, Shibayama M, Segovia J, Tsutsumi V, Muriel P. Hesperidin prevents liver fibrosis in rats by decreasing the expression of nuclear factor- $\mathrm{\kappa B}$, transforming growth factor- $\beta$ and connective tissue growth factor. Pharmacology. 2014; 94:80-89.

21. Tamayo LV, Gouvea LR, Sousa AC, Albuquerque RM, Teixeira SF, de Azevedo RA, Louro SR, Ferreira AK, Beraldo H. Copper (II) complexes with naringenin and hesperetin: cytotoxic activity against A 549 human lung adenocarcinoma cells and investigation on the mode of action. Biometals. 2016; 29:39-52.

22. Saiprasad G, Chitra P, Manikandan R, Sudhandiran G. Hesperidin alleviates oxidative stress and downregulates the expressions of proliferative and inflammatory markers in azoxymethane-induced experimental colon carcinogenesis in mice. Inflamm Res. 2013; 62:425-440.

23. Srirangam R, Hippalgaonkar K, Avula B, Khan IA, Majumdar S. Evaluation of the intravenous and topical routes for ocular delivery of hesperidin and hesperetin. J Ocul Pharmacol Ther. 2012; 28:618-627.

24. Tsai YH, Lee KF, Huang YB, Huang CT, Wu PC. In vitro permeation and in vivo whitening effect of topical hesperetin microemulsion delivery system. Int J Pharm. 2010; 388:257-262.

25. Lee YS, Huh JY, Nam SH, Moon SK, Lee SB. Enzymatic bioconversion of citrus hesperidin by Aspergillus sojae naringinase: enhanced solubility of hesperetin-7-Oglucoside with in vitro inhibition of human intestinal maltase, HMG-CoA reductase, and growth of Helicobacter pylori. Food Chem. 2012; 135:2253-2259.

26. Kosztyu P, Bukvova R, Dolezel P, Mlejnek P. Resistance to daunorubicin, imatinib, or nilotinib depends on expression levels of ABCB1 and ABCG2 in human leukemia cells. Chem Biol Interact. 2014; 219:203-210.

27. Bazylińska U, Pietkiewicz J, Rossowska J, Chodaczek G, Gamian A, Wilk KA. Polyelectrolyte oil-core nanocarriers for localized and sustained delivery of daunorubicin to colon carcinoma MC38 cells: the case of polysaccharide multilayer film in relation to PEG-ylated shell. Macromol Biosci. 2017; 17:5.

28. Varatharajan S, Panetta JC, Abraham A, Karathedath S, Mohanan E, Lakshmi KM, Arthur NM, Srivastava V, Nemani S, George B, Srivastava A, Mathews V, Balasubramanian P. Population pharmacokinetics of Daunorubicin in adult patients with acute myeloid leukemia. Cancer Chemother Pharmacol. 2016; 78:1051-1058.

29. Goorden SM, Buffart TE, Bakker A, Buijs MM. Liver disorders in adults: ALT and AST. Ned Tijdschr Geneeskd. 2013; 157:A6443-A6443.

30. Bonventre JV, Vaidya VS, Schmouder R, Feig P, Dieterle F. Next-generation biomarkers for detecting kidney toxicity. Nat Biotechnol. 2010; 28:436-440.

31. Flatmark K, Saelen MG, Hole KH, Abrahamsen TW, Fleten KG, Hektoen HH, Redalen KR, Seierstad T, Dueland S, Ree $\mathrm{AH}$. Individual tumor volume responses to short-course oxaliplatin-containing induction chemotherapy in locally advanced rectal cancer-targeting the tumor for radiation sensitivity?. Radiother Oncol. 2016; 119:505-511.

32. Ratajczak MZ, Jadczyk T, Schneider G, Kakar SS, Kucia M. Induction of a tumor-metastasis-receptive microenvironment as an unwanted and underestimated side effect of treatment by chemotherapy or radiotherapy. J Ovarian Res. 2013; 6:95.

33. Schneider G, Sellers ZP, Ratajczak MZ. Induction of a tumor-metastasis-receptive microenvironment as an unwanted side effect after radio/chemotherapy and in vitro 
and in vivo assays to study this phenomenon. Methods Mol Biol. 2016; 1516:347-360.

34. Chang CZ, Wu SC, Lin CL, Kwan AL. Curcumin, encapsulated in nano-sized PLGA, down-regulates nuclear factor $\kappa \mathrm{B}(\mathrm{p} 65)$ and subarachnoid hemorrhage induced early brain injury in a rat model. Brain Res. 2015; 1608:215-224.

35. Sato H, Fujimori M, Suzuki H, Kadota K, Shirakawa Y, Onoue S, Tozuka Y. Absorption improvement of tranilast by forming highly soluble nano-size composite structures associated with $\alpha$-glucosyl rutin via spray drying. Eur J Pharm Biopharm. 2015; 92:49-55.

36. Wu D, Zhang J, Wang J, Li J, Liao F, Dong W. Hesperetin induces apoptosis of esophageal cancer cells via mitochondrial pathway mediated by the increased intracellular reactive oxygen species. Tumour Biol. 2016; 37:3451-3459.

37. Si YX, Wang ZJ, Park D, Chung HY, Wang SF, Yan L, Yang JM, Qian GY, Yin SJ, Park YD. Effect of hesperetin on tyrosinase: inhibition kinetics integrated computational simulation study. Int J Biol Macromol. 2012; 50:257-262.

38. Liu Z, Sun Y, Hong H, Zhao S, Zou X, Ma R, Jiang C, Wang Z, Li H, Liu H. 3-bromopyruvate enhanced daunorubicininduced cytotoxicity involved in monocarboxylate transporter 1 in breast cancer cells. Am J Cancer Res. 2015; 5:2673.

39. Schreier VN, Pethő L, Orbán E, Marquardt A, Petre BA, Mező G, Manea M. Protein expression profile of HT-29 human colon cancer cells after treatment with a cytotoxic daunorubicin-GnRH-III derivative bioconjugate. PLoS One. 2014; 9:e94041.

40. Gardner RA, Thomson B, Hawkins DS. Substitution with doxorubicin for daunorubicin during induction for high risk pediatric acute lymphoblastic leukemia results in increased toxicity. Pediatr Blood Cancer. 2013; 60:338-339.

41. Goyal AK, Garg T, Rath G, Gupta UD, Gupta P. Chemotherapeutic evaluation of guar gum coated chitosan nanoparticle against experimental tuberculosis. J Biomed Nanotechnol. 2016; 12:450-463.

42. Xiao B, Ma L, Merlin D. Nanoparticle-mediated co-delivery of chemotherapeutic agent and siRNA for combination cancer therapy. Expert Opin Drug Deliv. 2017; 14:65-73.

43. Deshpande P, Dapkekar A, Oak MD, Paknikar KM, Rajwade JM. Zinc complexed chitosan/TPP nanoparticles: a promising micronutrient nanocarrier suited for foliar application. Carbohydr Polym. 2017; 165:394-401.

44. Kang L, Gao Z, Huang W, Wang Q. Nanocarrier-mediated co-delivery of chemotherapeutic drugs and gene agents for cancer treatment. Acta Pharm Sin B. 2015; 5:169-175.

45. Chen W, Yuan Y, Cheng D, Chen J, Wang L, Shuai X. Co-delivery of doxorubicin and siRNA with reduction and $\mathrm{pH}$ dually sensitive nanocarrier for synergistic cancer therapy. Small. 2014; 10:2678-2687.

46. Guo Q, Kuang L, Cao H, Li W, Wei J. Self-assembled mPEG-PCL-g-PEI micelles for multifunctional nanoprobes of doxorubicin delivery and magnetic resonance imaging and optical imaging. Colloids Surf B Biointerfaces. 2015; 136:687-693.

47. Shi S, Zhu X, Guo Q, Wang Y, Zuo T, Luo F, Qian Z. Selfassembled mPEG-PCL-g-PEI micelles for simultaneous codelivery of chemotherapeutic drugs and DNA: synthesis and characterization in vitro. Int J Nanomedicine. 2012; 7:1749-1759.

48. Zhang T, Wang H, Ye Y, Zhang X, Wu B. Micellar emulsions composed of mPEG-PCL/MCT as novel nanocarriers for systemic delivery of genistein: a comparative study with micelles. Int J Nanomedicine. 2015; 10:6175.

49. Xue B, Wang Y, Tang XH, Xire P, Wang Y, Luo F, Wu C, Qian Z. Biodegradable self-assembled MPEG-PCL micelles for hydrophobic oridonin delivery in vitro. J Biomed Nanotechnol. 2012; 8:80-89.

50. Fereshteh Z, Salavati-Niasari M. Effect of ligand on particle size and morphology of nanostructures synthesized by thermal decomposition of coordination compounds. J Biomed Nanotechnol. 2017; 243:86-104.

51. Kim SH, Park EJ, Lee CR, Chun JN, Cho NH, Kim IG, Lee S, Kim TW, Park HH, So I, Jeon JH. Geraniol induces cooperative interaction of apoptosis and autophagy to elicit cell death in PC-3 prostate cancer cells. Int J Oncol. 2012; 40:1683-1690.

52. Shrivastava A, Kuzontkoski PM, Groopman JE, Prasad A. Cannabidiol induces programmed cell death in breast cancer cells by coordinating the cross-talk between apoptosis and autophagy. Mol Cancer Ther. 2011; 10:1161-1172.

53. Shoeb M, Ramana KV, Srivastava SK. Aldose reductase inhibition enhances TRAIL-induced human colon cancer cell apoptosis through AKT/FOXO3a-dependent upregulation of death receptors. Free Radic Biol Med. 2013; 63:280-290.

54. Park HJ, Kim YJ, Leem K, Park SJ, Seo JC, Kim HK, Chung JH. Coptis japonica root extract induces apoptosis through caspase 3 activation in SNU-668 human gastric cancer cells. Phytother Res. 2005; 19:189-192.

55. Wu R, Tang $\mathrm{S}$, Wang $\mathrm{M}, \mathrm{Xu} \mathrm{X}$, Yao $\mathrm{C}$, Wang $\mathrm{S}$. MicroRNA-497 induces apoptosis and suppresses proliferation via the Bcl-2/Bax-Caspase9-caspase3 pathway and cyclin D2 protein in HUVECs. PLoS One. 2016; 11:e0167052.

56. Mandard AM, Denoux Y, Herlin P, Duigou F, van de Vijver MJ, Clahsen PC, Broek LV, Sahmoud TM, Henry-Amar M, van de Velde CJ. Prognostic value of DNA cytometry in 281 premenopausal patients with lymph node negative breast carcinoma randomized in a control trial. Cancer. 2000; 89:1748-1757.

57. Trihia H, Murray S, Price K, Gelber RD, Golouh R, Goldhirsch A, Coates AS, Collins J, Gertsch MC, Gusterson BA; International Breast Cancer Study Group. Ki-67 expression in breast carcinoma: its association with grading 
systems, clinical parameters, and other prognostic factors-a surrogate marker. Cancer. 2003; 97:1321-1331.

58. Viale G, Regan MM, Mastropasqua MG, Maffini F, Maffini E. Predictive value of tumor Ki-67 expression in two randomized trials of adjuvant chemoendocrine therapy for node-negative breast cancer. J Natl Cancer Inst. 2008; 100:207-212.

59. Moldovan GL, Pfander B, Jentsch S. PCNA controls establishment of sister chromatid cohesion during $\mathrm{S}$ phase. Mol Cell. 2006; 23:723-732.

60. Koundrioukoff S, Jónsson ZO, Hasan S, de Jong RN, van der Vliet PC, Hottiger MO, Hübscher U. A direct interaction between proliferating cell nuclear antigen (PCNA) and Cdk2 targets PCNA-interacting proteins for phosphorylation. J Biol Chem. 2000; 275:22882-22887.

61. Gillett C, Fantl V, Smith R, Fisher C, Bartek J, Dickson C, Barnes D, Peters G. Amplification and overexpression of cyclin D1 in breast cancer detected by immunohistochemical staining. Cancer Res. 1994; 54:1812-1817.

62. Lin SY, Xia W, Wang JC, Kwong KY, Spohn B, Wen Y, Pestell RG, Hung MC. $\beta$-catenin, a novel prognostic marker for breast cancer: its roles in cyclin D1 expression and cancer progression. Proc Natl Acad Sci U S A. 2000; 97:4262-4266.

63. Burandt E, Grünert M, Lebeau A, Choschzick M, Quaas A, Jänicke F, Müller V, Scholz U, Bokemeyer C, Petersen C, Geist S, Paluchowski P, Wilke C, et al. Cyclin D1 gene amplification is highly homogeneous in breast cancer. Breast Cancer. 2016; 23:111-119.
64. Chu IM, Hengst L, Slingerland JM. The Cdk inhibitor p27 in human cancer: prognostic potential and relevance to anticancer therapy. Nat Rev Cancer. 2008; 8:253.

65. Bedelbaeva K, Snyder A, Gourevitch D, Clark L, Zhang XM, Leferovich J, Cheverud JM, Lieberman P, HeberKatz E. Lack of p21 expression links cell cycle control and appendage regeneration in mice. Proc Natl Acad Sci U S A. 2010; 107:5845-5850.

66. Velec M, Craig T, Wang L, Russo M, Lindsay PE, Haddad CR, Kim JJ, Dawson LA. Predictors of liver toxicity following stereotactic body radiation therapy for hepatocellular carcinoma. Int J Radiat Oncol Biol Phys. 2015; 93:E175.

67. Ghosh S, Sarkar A, Bhattacharyya S, Sil PC. Silymarin protects mouse liver and kidney from thioacetamide induced toxicity by scavenging reactive oxygen species and activating PI3K-Akt pathway. Front Pharmacol. 2016; $7: 481$.

68. Li M, Tang Z, Lv S, Song W, Hong H, Jing X, Zhang Y, Chen X. Cisplatin crosslinked $\mathrm{pH}$-sensitive nanoparticles for efficient delivery of doxorubicin. Biomaterials. 2014; 35:3851-3864.

69. Crespo ME, Galvez J, Cruz T, Ocete MA, Zarzuelo A. Anti-inflammatory activity of diosmin and hesperidin in rat colitis induced by TNBS. Planta Med. 1999; 65:651-653.

70. Yamamoto M, Suzuki A, Hase T. Short-term effects of glucosyl hesperidin and hesperetin on blood pressure and vascular endothelial function in spontaneously hypertensive rats. J Nutr Sci Vitaminol. 2008; 54:95-98. 